\title{
Consequences of Violence Against Women: Amhara Regional State, East Gojjam Zone High-school and Preparatory Schools as a Case in Point
}

\author{
Genanew Jemberu Engida, Adane Mengest Tessma, Mulugeta Nega Gobeze \\ Department of Civic and Ethical Studies, Faculty of Social Science and Humanities, Debre Markos University, Debre Markos, Ethiopia \\ Email address: \\ genanewg1g2g3@gmail.com@GenanewJemberu.com (G. J. Engida), adanemengist@gmail.com@AdaneMengist.com (A. M. Tessma), \\ mnega41@gmail.com@MulugetaNega@.com(M. N. Gobeze)
}

\section{To cite this article:}

Genanew Jemberu Engida, Adane Mengest Tessma, Mulugeta Nega Gobeze. Consequences of Violence Against Women: Amhara Regional State, East Gojjam Zone High-school and Preparatory Schools as a Case in Point. Science, Technology \& Public Policy.

Vol. 4, No. 1, 2020, pp. 1-7. doi: 10.11648/j.stpp.20200401.11

Received: November 13, 2019; Accepted: November 28, 2019; Published: April 17, 2020

\begin{abstract}
Violence are different in its extent, and in advanced contraries men's are exposed for violence by women but in the Ethiopian context, men's are the perpetuator for violence and violence against women is common and has been growing from time to time. Cognizant of this gap, this study attempted to explore the consequences of violence against women: the case of East Gojjam Zone particularly in high-School and preparatory schools as a case in point. To meet the objective of the study, qualitative method with the case study design was used. In this study, eighteen semi structure interviewees, seven key informants' eight focus group discussants, were participated. All of the participants were selected by using non probability sampling technique specifically purposive sampling. Therefore, the data sources were primary data. Semi-structured interview, key informant interview and FGDs were used as a tool for collecting primary data. To analyze the data thematic analysis methods was employed. The findings from the study revealed that violence against women have so many consequences such as constricting the scope of women students activity, negative impact on women and girls health outcome, poor school performance, psychological impact, drop out, disrupting their lives and behavioral change and poverty. The study has concluded that violence against women at school level have several consequences. Based on the conclusion, recommendations are forwarded in line with the major finding of the study. Such as, Schools should create awareness for the communities to stop Violence against women and its negative consequences through different training, schools should strength gender club to build up the capacity of women students regarding on struggling violence against women to enhance self-confidence, to report and follow up on VAW at or around the schools, mainstream activities related to prevent violence against school women's in school system should be incorporated, provide training to parents in alternative methods for disciplining children and useful ideas on child rearing, women students should aware and eliminated peer pressure and others the motivating factors which exposed themselves for violence, the schools should create income-generating activities for schoolgirls coming from poor families to empower them economically.
\end{abstract}

Keywords: Violence, Consequences of Violence, Violence Against Women, Perpetuator of Violence

\section{Introduction}

\subsection{Background of the Study}

According to [1] WHO (2012) and Salamacis (2006) violence is a behavior against people liable to cause physical and psychological harm. Usually violence takes place among men and women social groups. In a developing countries violence against women could be domestic at home or outside (at school, on the road, workplaces and so on). It includes beating, rape, sexual abuse or harassment causing physical or psychological damage on women and degrades the status of women. Most violence is perpetrated by men against women [2] (Garcia, 1999). Gender-based violence is any undesirable act involving men and women, in which one sex (usually the women) are victims of physical, sexual and 
psychological harm, and the other (usually the male) are the perpetrators of the violent acts. In most African countries Violence against women, and particularly systematic rape, has frequently been used as a weapon of war against particular ethnic groups or entire populations [3] (Salamacis, 2006).

Violence against women, in its various forms, is endemic in communities and countries around the world, cutting across class, race, age, religion and national boundaries [4] (UN, 1993 and Scully, 2010). According to [5] Heise et al (1999), from one fifth to more than half all women have been physically assaulted by a spouse or male intimate in their life time this indicated that women are exposed for violence in the world.

Violence against women has been the most pervasive yet least recognized human rights abuse in the world. It could be domestic at home or outside (at school, on the road and workplace so on). It is an obstacle to equality, development, and peace and has negative impact on women's human right and their freedom, offence against the dignity and integrity of the victim and in all societies' women and girls are facing physical, sexual and psychological abuse [6] (Morrison and WHO, 2007; UN Secretary General, 2006, and United Nations 2008). It is also seen as a serious obstacle to development in developing countries [7] (ESCAP, 2007) and VAW has negative impact on school attendances, education and employment opportunities

Violence are universal sources of death, injury, and stress in the lives of women that cross lines of culture, age, ethnicity, economic status, and national boundary. Violence against women, as perpetrated through both individual and sovereign actions, has possessed a multitude of roots, including individualized cultural attitudes and society's lack of education about the profound harms caused by violence [8] (Ulrich, 2000). This study used to investigate the consequences of violence against women: the case of East gojjam zone. Furthermore, violence against women is a critical issue it needs much concern and this problem was chosen, because the researchers believe, it represents a significant topic worth examining.

There are different studies which were conducted in Ethiopia and abroad related to the issues. some of these studies [9] Jansen (2008) conducted a study on challenges to measuring violence against women, [10] Phillips (2011) reported on measuring domestic violence and sexual assault against women in Australia, further more [11] World Health Assembly (2014) conducted a research on strengthening the role of the health system in addressing violence, in particular against women and girls, and against children, and also [12] Path (2002) studied on violence against women: Effects on Reproductive Health.

In addition Alemmaya (2002) conducted a research on gender and Islam: how can violence are embedded in religious reflections [13] (Bagshaw, D. and Chung, D., 2000) also studied on women, men and domestic violence, Hearn J. et al (1996) reported on violence and gender relations: theories and interventions, more over [14] UNHCR (2003) reported on sexual and gender-based violence against refugees, returnees and internal displaced persons, in addition [15] WHO (2005) collected a data on women's health and domestic violence against women. Geneva, World Health Organization. As far as the researcher's knowledge is concerned, none of these studies focused on the consequences of violence against women: the case of East Gojjam Zone. And in current situation the issues of violence against women is prevail and becoming a serious problem in the study area which need farther investigation. In order to partially fill this gap, this study is focusing to investigate the consequences of violence against women: the case of East Gojjam zone.

\subsection{Objective of the Study}

The objective of this study is to investigate the consequences of violence against women: the case of East Gojjam zone. And this study will have the following significances: The study could create awareness to East Gojjam zone women and children affairs office, NGOs and other concerned body in order to intervene on the problem. This study will important in contributing knowledge about the consequences of VAW, It can also use as a secondary source for further studies related to the topic and will motivate other researchers to study further on the issue under study.

\section{Methodology}

In order to achieve the objectives of this research the researchers employed qualitative research approaches for its most advantage over quantitative approach. The aim to employ a qualitative approach to this study mainly emanate from the nature of the research which needs detail investigation about the consequences of VAW thorough word than numbers in depth. Case studies are strategy of inquiry in which the researchers explores in depth a program, event, activity, process or one or more individuals. Cases are bounded by time and activity and researchers collect detailed information using variety data collection procedures over a sustained period of time. In line with these points, the researchers employed case study design by considering East Gojjam Zone and the issue as a case.

The researchers used non probability sampling techniques and from non-probability sampling techniques, the researchers used purposive sampling technique. Therefore, the study area and the participants were selected by the researcher's purposively because the researchers were living in the city of the study area and by considering the participants had appropriate knowledge about the issue. The sample sizes were saturated with 25 participants. To address the objective of the study, the researchers used primary data and secondary data sources. The researchers used primary data sources because it gives first-hand information about the consequences of VAW. And the primary data were collected from high school and preparatory female students, school directors, teachers. And the secondary data were gathered 
from published and unpublished documents. The data were collected through semi structure interview, focus group discussion and key informants interview. From the various methods of qualitative data analyses the researchers used thematic and document analysis in order to analysis the consequences VAW in the case of East Gojjam Zone.

\section{Findings and Discussions}

This section presents the findings of the study obtained from semi structured-interviewee, key informant interviewee and focus group discussants which were discussed in the methodology part.

Demographic characteristics of participants.

Table 1. Demographic Characteristics of Semi Structure Interviewee.

\begin{tabular}{|c|c|c|c|}
\hline No & Code & Age & Grade level \\
\hline 1 & I 1 & 15 & 9 \\
\hline 2 & $\mathrm{I} 2$ & 14 & 9 \\
\hline 3 & $\mathrm{I} 3$ & 17 & 10 \\
\hline 4 & I4 & 17 & 10 \\
\hline 5 & I5 & 15 & 9 \\
\hline 6 & I6 & 15 & 9 \\
\hline 7 & I7 & 16 & 10 \\
\hline 9 & I9 & 17 & 9 \\
\hline 10 & I10 & 18 & 10 \\
\hline 11 & I11 & 19 & 11 \\
\hline 12 & $\mathrm{I} 12$ & 18 & 12 \\
\hline 13 & I13 & 19 & 12 \\
\hline 14 & I14 & 18 & 12 \\
\hline 15 & I15 & 17 & 11 \\
\hline 18 & I18 & 17 & 11 \\
\hline
\end{tabular}

Keys:-I = interviewee.

Table 2. Demographic Characteristics of Key Informants.

\begin{tabular}{lllll}
\hline No & Code & Sex & Educational Level & Job position \\
\hline 1 & KIS 1 & M & M. A & Director \\
2 & KIS 2 & F & M. A & Director \\
3 & KIS 3 & M & B. A & Teacher \\
4 & KIS 4 & M & B. A & Director \\
5 & KIS 5 & F & M. A & Teacher \\
6 & KIS 6 & M & B. A & Director \\
7 & KIS 7 & F & B. A & Director \\
\hline
\end{tabular}

Key;-KIS= key informants.

Table 3. Demographic Characteristics of Focus group discussants.

\begin{tabular}{llll}
\hline No & Code & Grade level & Age \\
\hline 1 & Fgdp 1 & 10 & 17 \\
2 & Fgdp 2 & 10 & 15 \\
3 & Fgdp 3 & 9 & 15 \\
4 & Fgdp 4 & 9 & 17 \\
5 & Fgdp 5 & 12 & 18 \\
6 & Fgdp 6 & 11 & 17 \\
7 & Fgdp7 & 12 & 19 \\
8 & Fgdp8 & 11 & 17 \\
\hline
\end{tabular}

Key;-Fgdp= focus group discussion participants.

\subsection{Consequences of Violence Against Women}

As the finding indicates that violence against women had so many consequences which could be generally grouped in social, economical, psychological and sexual consequences which are mentioned below.

\subsection{Consequences of Violence Against Women}

Constricting the scope of women students activity
Concerning on constricting the scope of women students activity the research participants described that violence against women limits the participation of women students in different aspects. One of the semi structure interviewee (10) described that:

Violence against women restricted women students' activity in different affairs and it affects on their academic arena. For example by fearing of violence women students were no study in library at opposite shifts and they were not 
volunteer to participate in different co-curricular activities like clubs. Even their relationships with male students and male teachers were very week because of regretting violence and this leads to affect their academic achievements.

Likewise the pervious researcher findings found out that VAW narrows women's options in almost every sphere of life, public and private at home, in school, in the workplace and in more community spaces. It limits their choices directly by destroying their health, disrupting their lives and constricting the scope of their activity and indirectly by eroding their self-esteem and self-confidence. In all of these ways, violence hinders women's full participation in society, including participation in the full spectrum of development [16] (Babur, 2007). Actual and threatened violence against women creates a pervasive atmosphere of fear that limits the lives of women, restricting their freedom of movement and their ability to participate in public decision making and affecting their standard of living (WHO, 2005) And social isolation is a consequence of women abuse. Women with strong family and friendship networks experience lower rates of violence [17] (Flood, 2007).

Negative impact on women's and girls' health outcomes

All most al research participants described that, Transmitted diseases and unsafe abortion were the consequences of violence against women. Regarding on negative out comes on women health outcomes. One of the focus group discussants (FGD 7) stated that:

Violence against women had many negative health impacts, like HIV/AIDS, and other transmitted disease, unwanted pregnancy and unsafe abortion because women students were not understood to use condom and post pills in time of sexual intercourse rather they wanted to withhold the information for their sexual partner.

Similarly, one of the key informants 'interviewee (KIS 7) described that:

Many women students are exposed for un-safe abortion. When I was collected preliminary data at Mary stop health institution and Gozamen Woreda clinic many students were exposed for un-wanted pregnancy and our women students were the clients to get the service of abortion.

The above research findings are similar with the previous research findings which conducted by [18] Middleton Lee S., (2013). According to him Violence against women and girls across their lifespan contributes disproportionately to poor health outcomes. Those experiencing violence encounter more health problems and incur significantly higher health care costs than those who have not experienced violence. Survivors visit health facilities more frequently (when they have access) without necessarily revealing the root cause of their health problem, yet the violence they experience is significant in shaping their mental and physical health and social well-being According to [19] WHO (2013), it is not a new phenomenon, nor are its consequences to women's physical, mental and reproductive health. violence against women-VAW- means any act of gender-based violence that results in, or is likely to result in, physical, sexual or psychological harm or suffering to women, including threats of such acts, coercion or arbitrary deprivation of liberty, whether occurring in public or in private life [20](United Nations, 1993). Young girls forced into marriage and into sexual relations may suffer health risks, including exposure to HIV/AIDS, and limited school attendance. One effect of sexual abuse is traumatic gynecologic fistula: an injury resulting from severe tearing of the vaginal tissues, rendering the woman incontinent and socially undesirable [21] (UN, 2016). Violence before and during pregnancy has serious health consequences for both mother and child. It leads to high-risk pregnancies and pregnancy-related problems, including miscarriage, pre-term labour and low birth weight [22] (UN, 2016).

Sexual assault can lead to post-traumatic stress disorder (PTSD), depression, anxiety, eating and sleeping disorders, suicidality, and a wide range of short- and long-term mental health struggles among children, teens, and adults. Perpetrators often target people with vulnerabilities, such as mental illness, because they may be less likely to report or when they do, less likely to be believed or viewed as credible. Sexual assault victims who also struggle with mental health issues or mental illnesses often face layers of social stigma, which can exacerbate their isolation and make it more difficult to access services [23] (Donna Greco and Sarah Dawgert, 2007).

Poor school performance

All most al research participants stated that poor school performance was the consequences of violence against women. Concerning on poor school performance one of the semi structured interviewee (I 5) described as follow:-

In our school we women students are faced violence by men students and youths who lived in the town. And when someone tries to violate us when we come out and come in the school we think about his violence rather than to think about our academic achievement. This leads us to have poor academic performance.

Likewise one of the focus group discussants (fgd 1) described that:

"There were students who drop out from the school because of violence". On the same way the previous research work stated that violence against school girls reduces their ability to concentrate on their lessons. The presence of sexual or physical violence in the family or on the way to and from school has a destructive effect on school girls' concentration in the classroom. For example, a girl who has experienced rape or attempted rape will be unable to concentrate on the teaching. School girls who face domestic violence (e.g., an abusive step-parent) are likely to attend lessons with a drained energy and emotion and consequently lose interest in the subjects being taught [24] (Save the children, 2008).

Sexual violence can seriously undermine a person's education, decreasing their earning potential and economic stability throughout the course of their lives. Child sexual abuse can severely reduce a child's school readiness and ability to concentrate. Teens and young adults also experience interruptions in their education as a result of sexual violence, often dropping out and entering the 
workforce without the skills they need to compete for wellpaying jobs. The most immediate consequence of a sexual assault during adolescence is a diminished investment in education. Lifetime earnings are considerably less for individuals who have been assaulted in adolescence, contributing to their propensity for economic insecurity and myriad of related issues (Donna Greco and Sarah Dawgert, 2007).

Safety, privacy concerns, post-traumatic stress disorder, depression, anxiety, sleep disturbances, and other physical complications from the assault may hinder a victim's ability to concentrate, do well on schoolwork or even attend school. Absenteeism or even temporary or permanent withdrawal from classes may result (ibid). In relation to academic functioning, children who experience higher levels of violence have lower abilities in reading, mathematics, and general knowledge [25] (Silverstein, Augustyn, Cabral, \& Zuckerman, 2006). A girl who has been verbally abused or sexually harassed is not likely to be able to concentrate on her study and complete homework on time [26] (Save the children, 2008).

Psychological impact

All most all research participants stated that violence against women had a psychological impact on women students. Regarding on psychological impacts one of the semi structured interviewee (I 14) explained that:

Violence against women had a psychological impact on women students. For-example in our class students talk about 2 girls who done abortion at marystop and others female students talking un friendly words by saying I was not found at marry stop center to done abortion by saying this women students who done abortion were regret to freely integrate in the class. Because of this they suffered a problem of isolation inside and outside the class room.

Likewise the previous research finding ensured that psychological problems may contribute to the development of substance abuse over time for women and that psychological problems themselves may be derivative of experiences of partner abuse. Student who are exposed to violence are blame themselves, feelings of guilt, worry, and anxiety that may affect academic output and healthy social interactions. Younger children exposed to violence are at a greater risk of experiencing delayed physiological, emotional, language, and cognitive development [27](Garnett M, 2013). Psychologically affected women display a lack of interest in social activities, have lowered self-esteem, avoid peer relations, maintain unhealthy relationships and exhibit increased rebellion and defiant behaviors in the school environment. Stress and trauma placed on youth are more likely to affect neurodevelopment and potentially may lead to alcohol usage [28] (Dube et al., 2006).

Drop out and School attendance

All most all research participants stated that drop out were one of the problem who women students were faced.

Regarding on drop out one of the focus group discussants Fgdp (8) stated that:

Some of women students were drop out from the school because of violence like unwanted pregnancy as a result of conflict with their parents. And some of women students were interrupted from the school by conceal with their boyfriend to another area.

Similarly the previous research finding found that save the children (2008) one of the immediate effects of violence on school girls is that it reduces their ability to attend classes. A girl who has been verbally abused or sexually harassed by her teacher is more likely to skip the teacher's class in order to avoid further abuse or harassment. Also a girl who has been sexually assaulted on the way to and from school is discouraged from going to school. Presence of excessive workload at home often leads to late arrival in school and consequently school girls may be forced to miss one or two subjects or whole school day because of the closed school gates.

In addition sexual violence can undermine a person's education from the outset, as early as preschool and as late as post-secondary education. Many victims' grades suffer in the aftermath of rape. Many drop out of school due to their experiences of trauma and fear. Violence pervades many public and private school settings throughout the country, with inner city and low-income communities impacted the most severely. Violence and the threat of violence can undermine an individual's learning potential and educational and professional trajectories (Donna Greco and Sarah Dawgert, 2007). A girl who has been verbally abused or sexually harassed is not likely to be able to concentrate on her study and complete homework on time. One ultimate effect of all such ill-treatment and discrimination is that girls will suffer a higher rate of grade repetition and eventual dropout from school (Save the children, 2008).

Eroding self-confidence and self esteem

Most of the researcher participants described that they faced a problem of eroding self-confidence and self-esteem because of violence. Regarding on eroding self-confidence and self-esteem one of the semi structured interviewee (I 14) stated that:

When I was faced violence inside the school and outside the school I blamed the GOD who creates me as women and when male students always cut cold me and said unfriendly words I feel lack of self-confidence and self esteem because of my gender. And I feel inferiority and I was thinking we women were not equal with male.

Disrupting their lives and Behavioral change

All most all research participants explained that Disrupting their lives and Behavioral changes were the problem when women students were faced. Concerning on Disrupting their lives and Behavioral change one of the focus group participants (fgdp 9) described as follows.

When I faced violence at the school and outside the school my conduct were totally changed and I would become noisy and angry. Sometimes I cried and these lead me to disrupt my life because I always clash of conflict with my family and I disagree with my family in any kind of issues when they tried to advise me.

Poverty 
Poverty were the consequences of violence and regarding on poverty the focus group participants (fgdp 2) were described

When women were not attend their school in wellmannered they would not contribute a lot to their country development through physical, economic and social participation. And this leads to poverty because women are half of the population in the world and the country would lack many human capitals when women were ignored from school because of violence.

This finding is similar with the previous research work by [29] Garcia (1999) which is violence sustained by inequality and in turn perpetuates inequality. Violence is associated with poverty, but it also perpetuates poverty by, for example, reducing women's opportunities for work outside home, their mobility and access to information influences women's ability to care for themselves and their children and associated with self-destructive behavior such as alcohol and drug abuse. Moreover, violence determines women's sense of self- worth, their sense of autonomy, their ability to feel and act as independent, capable women. Poverty also exacerbates violence by hampering women's ability to leave violent situation [30] (Buehler, et al 1998). Actual and threatened violence against women creates a pervasive atmosphere of fear that limits the lives of women, restricting their freedom of movement and their ability to participate in public decision making and affecting their standard of living (WHO, 2005).

[31] Michael Flood (2014) negative impacts on economic and social development men's violence against women have both direct and indirect impacts on work and employment. Violence has significant negative consequences for women's physical and mental health, both short and long-term, and in turn these diminish their workforce productivity and participation. Economic costs associated with victimization include absenteeism, lost productivity related to use of sick leave, distraction and lack of concentration, underperformance, poor workplace relationships, access to employment support services etc., and staff replacement. Domestic violence has wider impacts at work. Friends, family and colleagues may also take leave from work for various reasons, and staff may try to protect or support victims. It impedes women's capacity to gain and maintain employment [32] (McFerran, 2011) the evidence is that women with a history of domestic violence have a more disrupted work history, are consequently on lower personal incomes, have had to change jobs more often and are employed at higher levels in casual and part time work than women with no experience of violence. VAW has negative impacts on economic and social development. Women could not lend their labor or creative ideas fully if they are burdened with the physical and psychological scars of abuse [33] (Carrillo, 1992). Violence against women has a profound impact on workplaces. Key impacts of this violence include "higher rates of absenteeism, loss of productivity, reduced employee morale and increased need for support in the workplace for victims [34] (Wellsetal. 2013).

\section{Conclusion and Recommendations}

\subsection{Conclusion}

Based on the findings identified in this study the following conclusion is drawn. Violence against women in East Gojjame zone particularly in high-School and preparatory schools have many consequences such as, constricting the scope of women students activity, negative impact on women and girls health outcome, poor school performance, psychological impact, drop out, disrupting their lives and behavioral change and poverty. From this we can argue that violence against women in East Gojjame zone high-School and preparatory schools have many consequence. Generally, we can conclude that in order to cache up violence against women in East Gojjame zone high-School and preparatory schools, it needs the involvement of various actors. Therefore, the school administrative and academic staffs, the communities and students by themselves must be struggle continually.

\subsection{Recommendations}

Based on the major research findings, the researcher suggests the following recommendations:

Schools should create awareness for the communities to stop Violence against women and its negative consequences through different training.

Schools should be strength gender club to build up the capacity of women students regarding on struggling violence against women, to enhance self confidence, to report and follow up on VAW at or around the schools.

Mainstream activities related to prevent violence against school women's in school system should be incorporated.

Provide training to parents in alternative methods for disciplining children and useful ideas on child rearing.

Women students should aware and eliminated peer pressure and others the motivating factors which exposed them for violence.

The schools should create income-generating activities for schoolgirls coming from poor families to empower them.

\section{References}

[1] Alemmaya, M. (2002). Gender and Islam: how can violence are embedded in religious? Reflections. Documentation of the Forum on Gender. Panos Ethiopia, Addis Ababa, No, 7.

[2] Bagshaw, D. and Chung, D. (2000). Women, men and domestic violence. University of South Australia, Vienna.

[3] Buehler, J., Dixon, B., \& Toomey, K. (1998). Lifetime and annual incidence of intimate partner violence and resulting injuries - Georgia, 1995. MMWR: Morbidity and Mortality Weekly Report, 47, 849-853.

[4] Carrillo, R. (1992). Battered dreams: violence against women as an obstacle to development. New York: the free press. 
[5] Donna Greco and Sarah Dawgert, (2007). Poverty and Sexual Violence Building Prevention and Dube, S., et al. (2006). alcohol and initiating alcohol use during adolescence. Adolescent Education in Ethiopia.

[6] ESCAP. (2007). Violence against women: harmful traditional and cultural practices in the Asian and Pacific Region 26-27 April 2007.

[7] Flood, M. (2007). Background document for Preventing Violence Before It Occurs: A framework and background paper to guide the primary prevention of violence against women in Victoria. From a Parent's Perspective.

[8] Garcia-Moreno, C. (1999). Violence against Women, Gender and Health Equity. Harvard Center for Population and Development Studies, Working Paper Series 99.15. Cambridge, Massachusetts.

[9] Garnett M, (2013). The Effects of Violence on Academic Progress and Classroom Behavior: Health 38.

[10] Hearn et al. (1996). An assessment of violence against women in Lebanon: an exploratory research. European Journal of Business and Social Sciences, Vol. 4, No. 03, June 2015.

[11] Heise et al. (1999). Ending violence against women. Population reports, series L, 11. Baltimore: Johns Hopkins University School of Public Health. Intervention Responses.

[12] Jansen, H,.(2008). Challenges to measure violence against women. Geneva Foundation for Medical Research. (http://www.gfmer.ch/PGC_RH_2005/Research_design_in_st u.).

[13] McFerran, L. (2011). Safe at Home, Safe at Work? National Domestic Violence and the Workplace Survey (2011). Sydney: Australian Domestic and Family Violence Clearinghouse and Centre for Gender Related Violence Studies, University of New South Wales.

[14] Michael Flood. (2014). Preventing violence against women and girls. University of Wollongong.

[15] Middleton Lee S. (2013). 'Review of Training and Programming Resources on Gender-Based Violence against Key Populations.' Technical Paper. USAID's AIDS Support and Technical Assistance Resources, AIDSTAR Two, Task Order 2 and the International HIV/AIDS Alliance, Arlington, VA.

[16] Morrison \& World Health Organization: (2007). Ethical and safety recommendations for researching, documenting and monitoring sexual violence in emergencies. Geneva: WHO.

[17] Path. (2002). Violence Against Women: Effects on Reproductive Health. Outlook. Vol. 20, No. 1.

[18] Phillips J. (2011). Measuring domestic violence and sexual assault against women: a review of the literature and statistics. Parliamentary Library, Parliament of Australia.
[19] Salamacis. (2006). Gender Politics: Citizenship, Activism and Sexual Diversity, London: Pluto Press, p47

[20] Save the children. (2008). A Study on Violence against Girls in Primary Schools and on Girls.

[21] Scully. (2010). Expanding the concept of gender-based violence in peace building and development. Journal of Peace building and Development 5: 21-33.

[22] Silverstein, M., Augustyn, M., Cabral, H., \& Zuckerman, B. (2006). Maternal depression.

[23] Ulrich. (2000). Indiana Journal of Global Legal Studies, Vol. 7, No. pp. 629-654.

[24] UN Secretary General. (2006). In-depth study on all forms of violence against women: Report of the Secretary General, New York:

[25] UN. (2016). To end violence against women.

[26] UNHCR. (2003). Sexual and gender-based violence against refugees, returnees and internal displaced persons: Guideline for prevention and response.

[27] United Nations General Assembly. (1993). Declaration on the Elimination of Violence Against Women.

[28] United Nations. (1993, December 20). Declaration on the Elimination of Violence against Women. General Assembly, 85th plenary meeting. Document A/RES/48/104.violence exposure: Double jeopardy for child school functioning. Pediatrics, 118 (3).

[29] Wells, L., et al. (2013). Engaging Men and Boys in Domestic Violence Prevention: Opportunities and promising approaches. Calgary, AB: The University of Calgary, Shift: The Project to End Domestic Violence.

[30] WHO. (2005). WHO Multi-country study on women's health and domestic violence against women. Geneva, World Health Organization.

[31] WHO. (2012). Violence against women and girls.

[32] WHO. (2013). Global and regional estimates of violence against women: prevalence and health effects of intimate partner violence and non-partner sexual violence.

[33] World Health Assembly. (2014). Gender and Reproductive Rights: Working Definitions, http://www.who.int/reproductive-

health/gender/sexual_health.html\#1).

[34] World Health Organization. (2007). Ethical and safety recommendations for researching, documenting and monitoring sexual violence in emergencies. Geneva: WHO. 